\title{
Study of Mean Diameter of Superior Cerebellar Peduncles in Bangladeshi Cadavers
}

\author{
A. Q. M. Ataul Haque ${ }^{1}$, Mohsin Khalil ${ }^{2}$, Seheli Zannat Sultana ${ }^{3}$, Dider Hossain Chowdhury ${ }^{4}$, \\ Fakrul Amin Mohammad Hasanul Banna ${ }^{5}$ \\ Received: September 30, 2015 Accepted: August 23, 2016 \\ doi: http://dx.doi.org/10.3329/jemc.v6i3.29681
}

\begin{abstract}
Background: The neuronal organisation of the cerebellum has been studied in details by many researchers. But most of these have been performed on animals and diameter of superior cerebellar peduncle in humans remains inadequately studied. It has been observed by various workers that dimensions of different organs in Bangladeshi population vary from those of Western population. Objective: Aim of the present work was to measure diameter of superior cerebellar peduncle to make a standard for Bangladeshi population. Materials and Methods: This observational study was done by using nonprobability sampling technique and performed by examining 63 cerebellum. Out of them 40 postmortem human cerebellums were collected from Bangladeshi cadavers of both sexes (male 25 and female 15) aged 5 to 60 years and 23 cerebellums from caesarian section of intrauterine death cases of both sexes (male 14 and female 9) aged 34 to 41 weeks of gestation. Specimens were collected from dead bodies autopsied on different dates from April to September 2009 at the autopsy laboratory of Department of Forensic Medicine and prenatal cases from Gynaecology and Obstetrics Department of Mymensingh Medical College \& Hospital, Mymensingh. The collected specimens were grouped into three age groups - Group A (28 to 42 weeks of gestation), Group B (5 to 30 years) and Group C (31 to 60 years). The diameters of the superior cerebellar peduncles of both cerebellar hemispheres were measured by using slide calipers and expressed in millimeter $(\mathrm{mm})$. The measurement was taken after fixation into $10 \%$ formol saline. Results: The mean $( \pm S D)$ diameters of right superior cerebellar peduncle in Group A was $4.96 \pm 1.40$, in Group B $6.83 \pm 1.46$ and in Group $C$ was $6.61 \pm 1.34 \mathrm{~mm}$. The mean ( $\pm S D$ ) diameters of left superior cerebellar peduncle in Group A was $4.87 \pm 1.25$, in Group B $6.79 \pm 1.45$ and in Group C $6.48 \pm 1.37 \mathrm{~mm}$. Conclusion: No significant difference was observed between mean diameters of right and left superior cerebellar peduncles.
\end{abstract}

Key words: Superior cerebellar peduncle; Diameter; Bangladeshi cadaver

J Enam Med Col 2016; 6(3): 148-151

\section{Introduction}

The cerebellum is a very important part of central nervous system and it is the portion of brain lying behind and below the cerebrum. The cerebellum controls the smooth contraction of voluntary muscle and carefully coordinates their action in the maintenance of normal posture. ${ }^{1,2}$

The human cerebellum is an enormously impressive organ. ${ }^{3}$ It is the largest part of hindbrain and located in the posterior cranial fossa, behind the pons and the medulla oblongata. ${ }^{4-7}$ The cerebellum is a central part of the major circuit that links sensory to motor areas of the brain and is required for the coordination of fine

1. Associate Professor, Department of Anatomy, Khawza Younus Medical College, Sirajgonj

2. Professor, Department of Anatomy, Mymensingh Medical College, Mymensingh

3. Professor, Department of Anatomy, Mymensingh Medical College, Mymensingh

4. Associate Professor, Department of Anatomy, Enam Medical College, Savar, Dhaka

5. Associate Professor, Department of Anatomy, Enam Medical College, Savar, Dhaka

Correspondence A. Q. M. Ataul Haque, Email: atauldr@yahoo.com 
movement. In health, it provides corrections during movement, which are the basis for the precision and accuracy and it is critically involved in motor learning and reflex modification. It receives sensory information through spinal, trigeminal and vestibulocerebellar pathways and via the pontine nuclei, from the cerebral cortex and the tectum. Cerebellar output is mainly to those structures of the brain that control movement. Cerebellum enlarges enormously during first year of life, after that the rate of growth is slow. The increase in volume is partly due to increase in the size and not in number of the nerve cells and partly by the growth of the blood vessels, but it is mainly affected by the progressive myelination of the nerve fibres. ${ }^{7}$ Cerebellar cortex consists of three layers - outer molecular, intermediate Purkinje and inner granular. ${ }^{7}$ Four pairs of deep cerebellar nuclei in the medullary core of white matter form the output neurons, which are named from medial to lateral side as the nucleus fastigii, nucleus globosus, nucleus emboliformis and nucleus dentatus. ${ }^{7}$ These nuclei consist of multipolar neurons and receive axon terminals of Purkinje cells from the cerebellar cortex and collaterals from climbing and mossy fibres. The axons of the deep cerebellar nuclei are projected as the final efferent pathways through the superior and inferior cerebellar peduncles to the thalamus, red nucleus, brain stem reticular nuclei, inferior olivary and vestibular nuclei. Such output fibres do not provide collaterals to the neurons of the cerebellar cortex. Each dentate nucleus presents a crenated nuclear mass with the hilum directed ventro-medially. It belongs to the neocerebellum and receives projections from the hemispheric or lateral cortex. The axons of dentate nucleus leave through the hilum and the superior cerebellar peduncles and form dentato-rubrothalamic fibres which decussate in the tegmentum of the lower mid brain and connect with the intermediate (lateral) ventral nucleus.

Cerebellum contains more nerve cells (neurons) than all the rest of the brain combined, on an average 50 billion neurons. ${ }^{3,5,7}$ Purkinje cells form the centre of a functional unit of the cerebellar cortex. The total number of neurons in human cerebellum during development decreased significantly from early maturity to old age. ${ }^{8}$ Studies of the structural-functional organisation of different parts of the cerebellum continue to be relevant. The variety of cerebellar functions and the conditions associated with their impairments have led to multilateral studies of this organ. The neuronal organisation of the cerebellum has been studied in details by many researchers. But most of these studies have been performed on animals. Diameter of superior cerebellar peduncle in humans still remains inadequately studied. It has been observed by various workers that dimensions of different organs in Bangladeshi population vary from those of Western population. In this perspective we designed to study on diameter of superior cerebellar peduncle in humans to make a standard for Bangladeshi population.

\section{Materials and Methods}

This observational study was done by examining 63 cerebellums. Of these 40 were postmortem human cerebellums collected from Bangladeshi cadavers (male 25 and female 15) aged 5 to 60 years and 23 cerebellums were of dead fetuses from caesarian section (male 14 and female 9) aged 34 to 41 weeks of gestation. Specimen containing cerebellum was collected from dead bodies autopsied on different dates from April to September 2009 at the autopsy laboratory of Department of Forensic Medicine and Gynaecology and Obstetrics department of Mymensingh Medical College, Mymensingh. All the collected specimens of postnatal cases were from medico-legal cases (suicidal, homicidal, or accidental death) and the specimen of foetus from intra-uterine death cases (eclampsia, antepartum haemorrhage, obstructed labour). Grossly injured cases involving head-neck region and cerebellum of decomposed bodies were excluded. The specimen was labelled with a specimen number, recording age and sex of the cadaver and then fixed in $10 \%$ formalin solution, by floating freely in a suitable container with a lid. The specimen was allowed to fix for a period of one or two weeks. The present study was done with these fixed specimens in spite of some hardening and shrinking of tissue brought about by fixation. These could not be avoided at the brains because in fresh state these were too soft to handle. It took one to two weeks for these to get sufficiently hard to allow normal handling and dissection to be carried out. The collected samples were divided into three groups - Group A (34 to 41 weeks of gestation), Group B (5 to 30 years) and Group C (31 to 60 years). Measurement was taken after fixation in $10 \%$ formol saline. The diameters of the superior cerebellar peduncles of both cerebellar hemispheres were measured by using slide calipers and expressed in millimeter (mm). Appropriate statistical analysis was done using computer based statistical package, SPSS 
(Statistical Package for Social Science) 14.0 to evaluate the significance of variance between the different findings.

\section{Results}

\section{Mean diameter of right superior cerebellar peduncles}

The maximum mean diameters of right superior cerebellar peduncles were 9.0, 9.5 and $9.5 \mathrm{~mm}$ in Group A, Group B and Group C respectively. The minimum mean diameters of right superior cerebellar peduncles were $2.5,4.5$ and $4.5 \mathrm{~mm}$ respectively in these groups. The mean $( \pm \mathrm{SD})$ diameters of right superior cerebellar peduncles were $4.96 \pm 1.40 \mathrm{~mm}$ in Group A, $6.83 \pm 1.46$ $\mathrm{mm}$ in Group B and $6.61 \pm 1.34 \mathrm{~mm}$ in Group C (Table I). The mean diameter of right superior cerebellar peduncles was maximum $(6.83 \mathrm{~mm})$ in Group B and minimum $(4.96 \mathrm{~mm})$ in Group A.

The mean differences of mean diameters of right superior cerebellar peduncle between Groups $\mathrm{A}$ and $\mathrm{B}$ and between Groups $\mathrm{A}$ and $\mathrm{C}$ were statistically highly significant but mean differences between Group B and Group C was statistically not significant.

Table II depicts that the mean diameter of right superior cerebellar peduncle was higher in female $(6.14 \pm 0.31$ $\mathrm{mm}$ ) than that of in male $(6.06 \pm 0.28 \mathrm{~mm})$ but statistically was not significant.

Table I: Mean diameters of the right superior cerebellar peduncles of different age groups

\begin{tabular}{|l|c|c|}
\hline \multicolumn{1}{|c|}{ Groups } & $\begin{array}{c}\text { Mean diameter }(\mathrm{mm}) \\
\text { (Range) }\end{array}$ & p values \\
\hline Group A (n=23) & $\begin{array}{c}4.96 \pm 1.40 \\
(2.5-9.0)\end{array}$ & A vs B: 0.000 \\
\hline Group B (n=23) & $\begin{array}{c}6.83 \pm 1.46 \\
(4.5-9.5)\end{array}$ & A vs C: 0.001 \\
\hline Group C (n=17) & $\begin{array}{c}6.61 \pm 1.34 \\
(4.5-9.5)\end{array}$ & B vs C: 0.621 \\
\hline & & \\
\hline
\end{tabular}

Table II: Comparison of mean diameters of right superior cerebellar peduncles between male and female

\begin{tabular}{|c|c|c|c|}
\hline Sex & $\begin{array}{c}\text { Mean }( \pm) \text { SE } \\
\text { diameter }(\mathrm{mm})\end{array}$ & $\mathrm{t}$ value & $\mathrm{p} \mathrm{value}$ \\
\hline Male $(\mathrm{n}=39)$ & $6.06 \pm 0.28$ & 0.20 & 0.844 \\
\hline Female $(\mathrm{n}=24)$ & $6.14 \pm 0.31$ & & \\
\hline
\end{tabular}

\section{Mean diameter of left superior cerebellar peduncle}

The maximum mean diameters of left superior cerebellar peduncles were $8.0,9.0$ and $9.0 \mathrm{~mm}$ in Group A, Group B and Group C respectively. The minimum mean diameters of left superior cerebellar peduncles were $2.5,4.5$ and $4.3 \mathrm{~mm}$ respectively in these groups. The mean ( \pm SD) diameters of left superior cerebellar peduncles were $4.87 \pm 1.25 \mathrm{~mm}$ in Group A, $6.79 \pm 1.45 \mathrm{~mm}$ in Group B and $6.48 \pm 1.37$ $\mathrm{mm}$ in Group C (Table III). The mean diameter of left superior cerebellar peduncles was maximum (6.79 $\mathrm{mm}$ ) in Group B and minimum (4.87 mm) in Group A.

The mean differences of mean diameters of left superior cerebellar peduncle between Group A and Group B and between Group A and Group C were statistically highly significant but mean difference between Group B and Group C was statistically not significant.

Table IV depicts that the mean diameters of left superior cerebellar peduncles was higher in female than that of in male but statistically not significant. Table V depicts that the mean diameter of the superior cerebellar peduncle was higher on right side than that on left side but statistically not significant.

Table III: Mean diameters of the left superior cerebellar peduncles in different age groups

\begin{tabular}{|l|c|c|}
\hline \multicolumn{1}{|c|}{ Groups } & $\begin{array}{c}\text { Mean diameter (mm) } \\
\text { (Range) }\end{array}$ & p values \\
\hline Group A (n=23) & $\begin{array}{c}4.87 \pm 1.25 \\
(2.5-8.0)\end{array}$ & A vs B: 0.000 \\
\hline Group B (n=23) & $\begin{array}{c}6.79 \pm 1.45 \\
(4.5-9.0)\end{array}$ & A vs C: 0.000 \\
\hline Group C (n=17) & $\begin{array}{c}6.48 \pm 1.37 \\
(4.3-9.0)\end{array}$ & B vs C: 0.473 \\
\hline
\end{tabular}

Table IV: Comparison of mean diameters of left superior cerebellar peduncles between male and female

\begin{tabular}{|c|c|c|c|}
\hline Sex & $\begin{array}{c}\text { Mean }( \pm) \text { SE } \\
\text { diameter (mm) }\end{array}$ & t value & p value \\
\hline Male $(\mathrm{n}=39)$ & $5.98 \pm 0.27$ & 0.11 & 0.916 \\
\hline Female $(\mathrm{n}=24)$ & $6.03 \pm 0.30$ & & \\
\hline
\end{tabular}


Table V: Comparison of mean diameters of superior cerebellar peduncles between right and left sides

\begin{tabular}{|c|c|c|c|}
\hline Sides & $\begin{array}{l}\text { Mean }( \pm) \text { SE } \\
\text { diameter }(\mathrm{mm})\end{array}$ & t value & p value \\
\hline Right $(\mathrm{n}=63)$ & $6.09 \pm 0.21$ & 0.29 & 0.778 \\
\hline Left $(\mathrm{n}=63)$ & $6.01 \pm 0.20$ & & \\
\hline
\end{tabular}

\section{Discussion}

In the present study, it was found that the mean $( \pm \mathrm{SD})$ diameters of right superior cerebellar peduncle in Group A was $4.96 \pm 1.40$, in Group B $6.83 \pm 1.46$ and in Group C $6.61 \pm 1.34 \mathrm{~mm}$. In this study it was also found that statistically there was no significant difference between mean diameters of right superior cerebellar peduncle of male and female. Very few studies were found to compare the findings of our study. Szabó et $\mathrm{al}^{9}$ also observed that there was no significant difference between cerebellar volumes of male and female.

In present study, it was found that the mean $( \pm \mathrm{SD})$ diameter of left superior cerebellar peduncle in Group A was $4.87 \pm 1.25$, in Group B $6.79 \pm 1.45$ and in Group C $6.48 \pm 1.37 \mathrm{~mm}$ respectively. In the present study it was also found that statistically there was no significant difference between mean diameters of left superior cerebellar peduncles of male and female. It was also observed in the present study that there was statistically no significant difference between mean diameters of right and left superior cerebellar peduncles. It is consistent with the findings of Szabó et al. $^{9}$
The result of the present study will enrich the information pool on diameter of superior cerebellar peduncle of Bangladeshi people. To establish a standard for Bangladeshi people, further study is required by using large number of samples from different parts of Bangladesh.

\section{References}

1. Snell RS. Clinical neuroanatomy. $8^{\text {th }}$ edn. Baltimore: Lippincott Williams and Wilkins, 2008: 219-240.

2. Ross MH, Kaya IG, Pawlina W. Histology: a text and atlas. $5^{\text {th }}$ edn. Philadelphia: Lippincott Williams \& Wilkins 2006: 322-323, 360.

3. Leiner HC, Leiner AL. 'The treasure at the bottom of the brain', new horizons for learning, 1997. Available at: http://www.newhorizons.org. Accessed December 2009.

4. Turlough MJF. Neuroanatomy. In: Gray's anatomy: the anatomical basis of clinical practice. $39^{\text {th }}$ edn. London: Churchill Livingston, 2005: 353-368.

5. Chaurasia BD. Human anatomy regional and applied (vol 3). $4^{\text {th }}$ edn. Bangalore: CBS Publishers and Distributor, 2007: 233-226.

6. Sinnatamby CS. Last's anatomy: regional and applied. $11^{\text {th }}$ edn. London: Harcourt Publishers Limited, 2006: 479-481.

7. Datta AK. Essentials of neuroanatomy (part 4). $4^{\text {th }}$ edn. Kolkata: Current Books International, 2005: 159-173.

8. Khutoryan BM. Quantitative characterization of the cellular elements of human cerebellar nuclei at different ages. Neurosci Behav Physiol 2005; 35(1): 5-7.

9. Szabó CA, Lancaster JL, Xiong J, Cook C, Fox P. MR imaging volumetry of subcortical structures and cerebellar hemispheres in normal persons. AJNR Am Neuroradial 2003: 24: 644-647. 